\title{
Abdominal Cocoon in an Adolescent Male
}

\author{
Shakya VC, ${ }^{1}$ Agrawal CS, ${ }^{1}$ Rajbanshi SK, ${ }^{1}$ Pradhan $A,{ }^{2}$ Khaniya $S,{ }^{1}$ Adhikary ${ }^{1}$
}

\author{
${ }^{1}$ Department of Surgery \\ ${ }^{2}$ Department of Pathology \\ B P Koirala Institute of Health Sciences \\ Dharan, Nepal
}

Corresponding Author

Vikal Chandra Shakya

Department of Surgery

B. P. Koirala Institute of Health Sciences

Dharan, Nepal

Email: vikalcsh@yahoo.com

\begin{abstract}
Abdominal cocoon is an uncommon peritoneal condition characterized by partial or complete encasement of small bowel by a thick rind of fibrous tissue and adhesions. Only few cases of this disease have been reported in world literature. The etiology of this condition is unknown, and most often it is found in adolescent girls from tropical or subtropical countries, and usually diagnosed incidentally on exploration. Surgery (membrane dissection and extensive adhesiolysis) is the treatment of choice. Here, we report a case of abdominal cocoon in a 20 -year-old male patient, with a brief review of the literature.
\end{abstract}

\section{KEYWORDS}

Abdominal cocoon; adhesiolysis; intestinal obstruction

Citation

Shakya VC, Agrawal CS, Rajbanshi SK, Pradhan A, Khaniya $\mathrm{S}$, Adhikary S. Abdominal Cocoon in an Adolescent Male Kathmandu Univ Med J 2012;10(4):83-86.

\section{INTRODUCTION}

"Abdominal cocoon" is a rare condition of unknown etiology occurring mostly in adolescent girls living in tropical and subtropical regions. ${ }^{1}$ It was first described by Foo et al. ${ }^{2}$ It is characterized by the encasement of the small bowel by a fibro-collagenic membrane leading to its clustering, causing intestinal obstruction. ${ }^{1}$ Only about 50 reports of this disease have been found in world literature. ${ }^{1}$ Preoperative diagnosis of this entity is difficult, requires a high index of clinical suspicion and is usually incidentally diagnosed on laparotomy. Here we report a case of abdominal cocoon in a 20-year-old male patient.

\section{CASE REPORT}

A 20-years-old male presented in the emergency of our hospital with complaints of abdominal pain, vomiting, nonpassage of stool and flatus and abdominal distension for last two days. He had intermittent episodes of abdominal pain and vomiting without abdominal distension for last one year, was empirically diagnosed to have abdominal tuberculosis outside and kept on anti-tubercular treatment for last four months. There was no history of peritonitis, abdominal surgery or pulmonary tuberculosis. General physical examination revealed mild dehydration. His pulse was $110 /$ minute, temperature $37.8^{\circ} \mathrm{C}$, blood pressure $130 / 70 \mathrm{mmHg}$. There was no cyanosis or jaundice. No abnormalities of the chest or cardiovascular system were found. On per-abdominal examination, it was found to have predominant fullness in the lower half of the abdomen alongwith mild tenderness and rigidity. There was no hepatomegaly or splenomegaly and rectum was empty. The bowel sounds was exaggerated. His hemoglobin was $12.9 \mathrm{~g} \%$, total leukocyte count 16,765 cells/ml with $75 \%$ neutrophils, other blood chemistry and urine analysis were normal. The abdominal radiograph showed multiple airfluid levels predominantly in the lower abdomen (Fig 1). A clinical diagnosis of mechanical small bowel obstruction was made provisionally, and emergency laparotomy was performed through a midline incision. Intra-operatively, it was found that the omentum and the small bowel loops were difficult to dissect from the parietal peritoneum, 


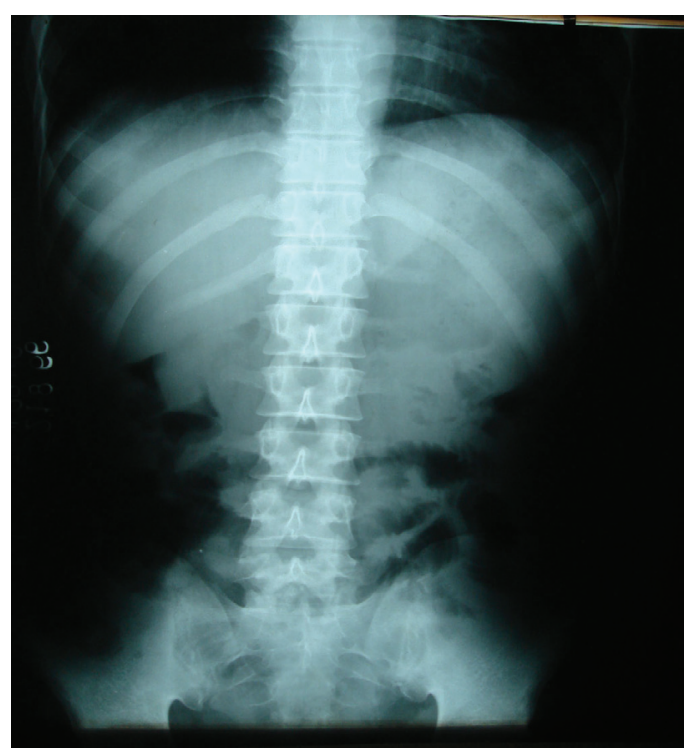

Figure 1. A plain abdominal radiograph showing multiple bowel loops predominantly in the lower abdomen.

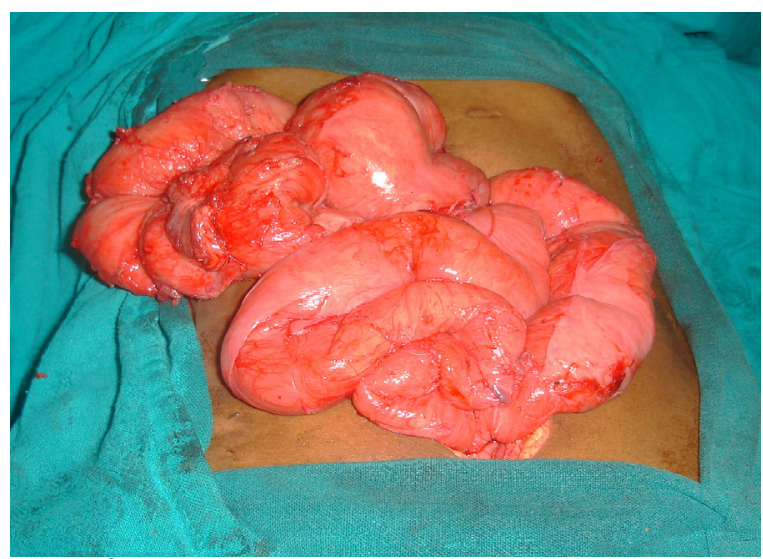

Figure 3. After adhesiolysis, small bowel loops are visible properly.

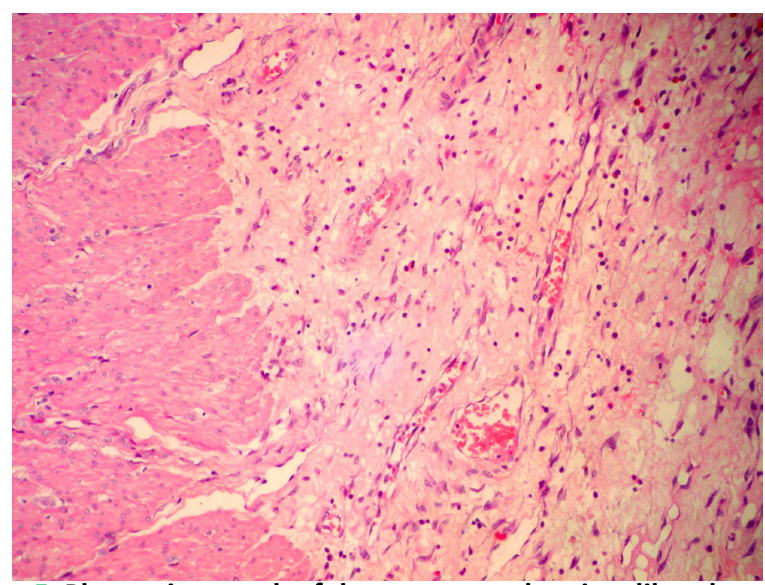

Figure 5. Photomicrograph of the omentum showing dilated and congested blood vessels and marked fibrosis (X10, H\&E stain).

they were so intimately adherent to each other at the anterior aspect, that individual loops were almost indistinguishable, giving a suspicion of abdominal cocoon (Fig 2). A plane between the bowel loops was found with difficulty at one point, and using a combination of blunt and sharp dissection, adhesionolysis was done. There was

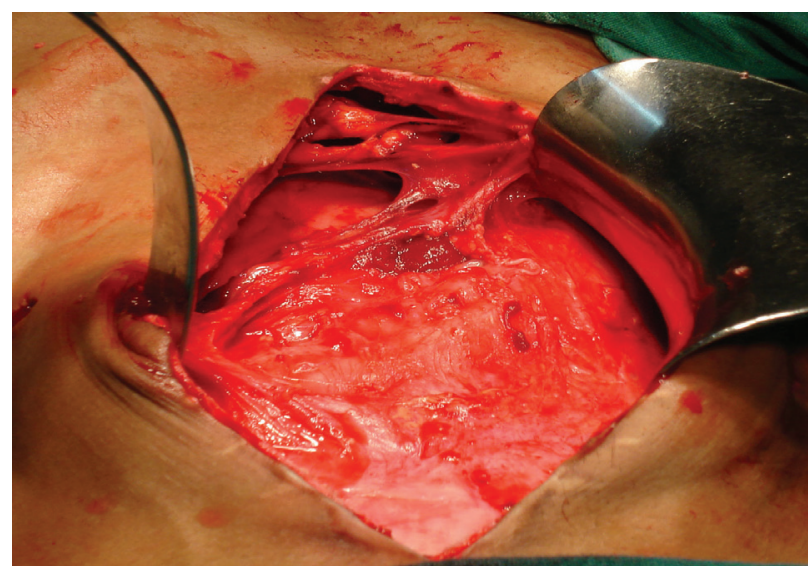

Figure 2. Laparotomy showing intimate adhesions of the bowel loops and omentum, making individual loops indistinguishable (abdominal cocoon).

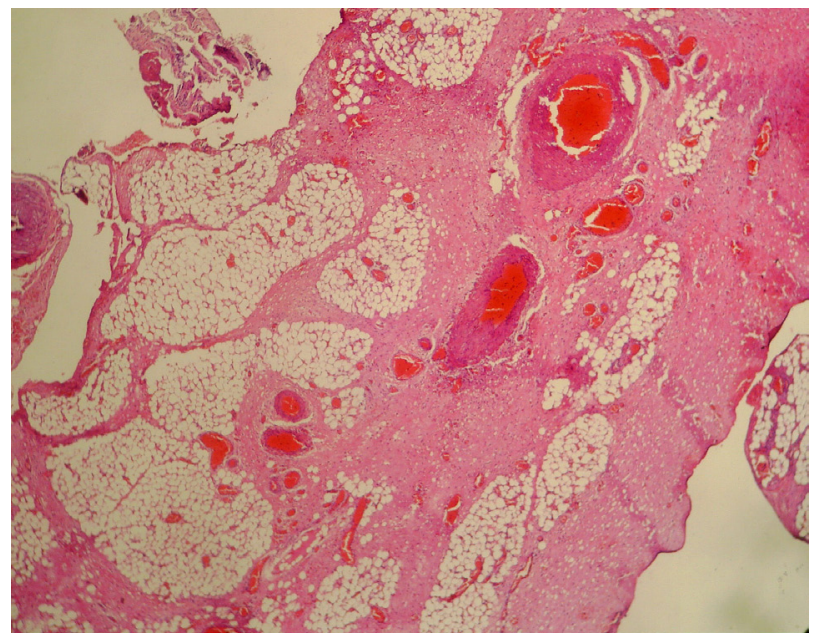

Figure 4. Photomicrograph of the omentum showing dilated and congested blood vessels and marked fibrosis (X10, H\&E stain).

no perceptible separate membrane. (fig The whole small bowel was freed; during adhesiolysis, a large perforation occurred at proximal ileum, and after resection of about $20 \mathrm{~cm}$ of the ileum, proximal ileostomy and distal mucous fistula was made. The resected bowel and the omentum were sent for histopathology. On microscopy, the omental tissue showed dilated and congested blood vessels and marked fibrosis; the serosa of the resected bowel showed thickening, mixed inflammatory cell infiltrates, consisting of neutrophils, eosinophils and lymphocytes alongwith fibrosis and congestion (Fig 4,5). A diagnosis of idiopathic sclerosing encapsulating peritonitis (abdominal cocoon) was established, due to intraoperative findings and by exclusion of other probable pathologies. The stoma started to function on $3^{\text {rd }}$ postoperative day; he was orally given on $4^{\text {th }}$ postoperative day, and was discharged on the $6^{\text {th }}$ day. The ileostomy was closed six months after the initial operation, and he is on regular follow-up for the last one year without any bowel symptoms. 


\section{DISCUSSION}

Abdominal cocoon is an uncommon peritoneal condition characterized by partial or complete encasement of small bowel by a thick rind of fibrous tissue and adhesions, causing clustering of the bowel and intestinal obstruction. ${ }^{1}$ The disease primarily involves small bowel, but can extend to involve other organs like the large intestine, liver and stomach. ${ }^{1,3}$

Abdominal cocoon can be idiopathic or secondary. Foo et al first described the idiopathic form, which is more common. ${ }^{2}$ It generally affects adolescent girls, and is found to be more common in tropical and subtropical countries of the world, especially China, Malaysia, Singapore, Pakistan, India, Nigeria, Kenya, Saudi Arabia, Israel, and South Africa. ${ }^{4-6}$ Although its etiology is still unknown, subclinical primary viral peritonitis, as an immunological reaction to gynecological infections, or due to retrograde menstruation, and retrograde peritonitis via the fallopian tubes have been suggested for its pathogenesis, probably due to its increased associated incidence in women. ${ }^{2}$ The secondary form is most commonly associated with chronic ambulatory peritoneal dialysis. ${ }^{7,8}$ It has also been described in association with prolonged practolol therapy, sarcoidosis, systemic lupus erythematosus, indwelling abdominal catheters (specifically ventriculoperitoneal and peritoneovenous shunts), orthotopic liver transplantation, liver cirrhosis, intraperitoneal instillation of drugs, recurrent peritonitis and tuberculous pelvic inflammatory disease. ${ }^{9-13}$

These patients usually present with features of acute or subacute small bowel obstruction, symptoms of chronic obstruction and weight loss, and/or pain associated with an abdominal lump. ${ }^{5,14}$ A pre-operative diagnosis is usually very difficult and requires a high index of clinical suspicion. Most cases are diagnosed intraoperatively during laparotomy performed for intestinal obstruction.

\section{REFERENCES}

1. Devay AO, Gomceli I, Korukluoglu B, Kusdemir A. An unusual and difficult diagnosis of intestinal obstruction: the abdominal cocooncase report and review of the literature. World J Emerg Surg 2006;1:8.

2. Foo KT, Ng KC, Rauff A, Foong WC, Sinniah R. Unusual small intestinal obstruction in adolescent girls: the abdominal cocoon. $\mathrm{Br} J$ Surg 1978;65:427-30.

3. Deeb LS, Mourad FH, El-Zein YR, Uthman SM. Abdominal cocoon in a man: preoperative diagnosis and literature review. J Clin Gastroenterol 1998;26:148-50.

4. Akca T, Ocal K, Turkmenoglu O, Bilgin O, Aydin S. Abdominal cocoon. Arch Surg 2006;141:943.

5. Yoon YW, Chung JP, Park HJ. A case of abdominal cocoon. J Korean Med Sci 1995;10:220-5.

6. Tu JF, Huang XF, Zhu GB, Liao Y, Jiang FZ. Comprehensive analysis of 203 cases with abdominal cocoon. Zhonghua Wei Chang Wai Ke Za Zhi 2006;9:133-5.

7. Serafimidis C, Katsarolis I, Vernadakis S. Idiopathic sclerosing encapsulating peritonitis (or abdominal cocoon). BMC Surgery 2006;6:3.
Plain radiographs of the abdomen may suggest features of intestinal obstruction. A preoperative diagnosis has been made in recent reports by a combination of barium followthrough and computed tomography of the abdomen. ${ }^{3,15,16}$ Barium meal follow-through may show delayed transit of contrast and clustering of the bowel loops in the pelvis. ${ }^{15}$ Pre-operative CT findings may include clumping of small bowel loops in the centre of the abdomen encased by a soft-tissue density mantle, peritoneal thickening and calcification, clumping of small bowel loops, and loculated fluid collections. ${ }^{3,16}$ Histopathological examination shows thickened vascular fibrocollagenous tissue, with or without chronic inflammatory reaction evidenced by lymphocytic and plasma cell infiltrates.

The treatment of abdominal cocoon has generally been described as dissection and adhesiolysis, which is usually sufficient. Resection is indicated only if the bowel is non-viable and grossly damaged during dissection, as in our case. Stoma has to be made in the most proximally located perforated region. Diagnostic laparoscopy and laparoscopic adhesiolysis has also been effective in the management of this disease. ${ }^{17}$ Though prognosis is said to be excellent, follow-up has also shown recurrence, some resolving on conservative management and others needing reoperation. ${ }^{6,14,18}$ Small bowel intubation has also been used with the hope of decreasing the recurrence as in postoperative adhesive obstruction. ${ }^{19}$

\section{CONCLUSION}

Abdominal cocoon is a rare condition, and the preoperative diagnosis is usually difficult. Recurrent episodes of small intestinal obstruction not attributable to other causes combined with relevant imaging findings should point to suspicion of this disease. Surgery is important in its management. Careful dissection and adhesiolysis releasing the small intestine usually leads to recovery.

8. Kawaguchi $\mathrm{Y}$, Kawanishi H, Mujais S, Topley N, Oreopoulos DG. Encapsulating peritoneal sclerosis: definition, etiology, diagnosis, and treatment. International Society for Peritoneal Dialysis Ad Hoc Committee on Ultrafiltration Management in Peritoneal Dialysis. Perit Dial Int 2000;20:S43-5.

9. Hunt D, Frew JL. Pericarditis and peritonitis associated with practolol therapy. Br Med J 1975;1:92-3.

10. Maguire D, Srinivasan P, O'Grady J, Rela M, Heaton ND. Sclerosing encapsulating peritonitis after orthotopic liver transplantation. Am J Surg 2001;182:151-4.

11. Rastogi R. Abdominal cocoon secondary to tuberculosis. Saudi J Gastroenterol 2008;14:139-41.

12. Cheijfec G, Reyes C, Stanley MM, Greenlee HB, Gould VE. Diffuse peritoneal fibromatosis associated with peritoneo-venous shunt in patients with cirrhosis. Lab Invest 1983;48:15A.

13. Hunt D, Frew JL. Pericarditis and peritonitis associated with practolol therapy. Br Med J 1975;1:92-3. 
14. Célicout B, Levard H, Hay J, Msika S, Fingerhut A, Pelissier E. Sclerosing encapsulating peritonitis: early and late results of surgical management in 32 cases. French Associations for Surgical Research. Dig Surg 1998;15:697-702.

15. Navani S, Shah P, Pandya S, Doctor N. Abdominal cocoon--the cauliflower sign on barium small bowel series. Indian J Gastroenterol 1995;14:19.

16. Wig JD, Gupta SK. Computed tomography in abdominal cocoon. J Clin Gastroenterol 1998;27:259-60.
17. Makam R, Chamany T, Ramesh S, Potluri VK, Varadaraju PJ, Kasabe P. Laparoscopic management of abdominal cocoon. J Minim Access Surg 2008;4:15-7.

18. Ping Xu, Li-Hua Chen, You-Ming Li. Idiopathic sclerosing encapsulating peritonitis (or abdominal cocoon): a report of 5 cases. World $J$ Gastroenterol 2007;13:3649-51.

19. Samarasam I, Mathew G, Sitaram V, Perakath B, Rao A, Nair A. The abdominal cocoon and an effective technique of surgical management. Trop Gastroenterol 2005;26:51-3. 